\title{
HOARSENESS OF VOICE
}

\author{
DR. MUHAMMAD SAEED, MBBS, FCPS \\ Assistant Professor ENT \\ Punjab Medical College \\ Allied Hospital Faisalabad.
}

\author{
DR. FAROOQ AHMED MIAN, MBBS, FCPS \\ Professor of ENT \\ Punjab Medical College Faisalabad.
}

\begin{abstract}
Objectives: To evaluate the etiology of hoarseness of voice. Design: Prospective Setting: Department of ENT Allied Hospital Faisalabad. Period: From Jan 2001 to Dec 2004. Material and Methods: The majority of patients were admitted through ENT out patient department. The data was collected on the basis of history physical examination, investigations, management and follow up. Results: Total 200 patients suffering from hoarseness of voice 150 males $(75 \%)$ and 50 females (25\%) between 10 to 70 years of age. The highest incidence was seen during fourth and fifth decade of life $(65 \%)$. The majority of patients were belonging to poor class $(75 \%)$. The most common etiological factor was infection (30\%). Conclusion: Hoarseness is the commonest symptom of laryngeal disorders and it should not be ignored if it persists for more than three weeks and does not respond to conventional treatment, this will prevent delay in diagnosis and proper management.
\end{abstract}

Key words: Hoarseness, Larynx .

\section{INTRODUCTION}

Hoarseness is vague term that patient often uses to describe a change in quality of voice ranging from voice harshness to voice weakness ${ }^{1}$. The hoarseness refers to laryngeal dysfunction caused by abnormal vocal cord vibrations ${ }^{2}$.

There are three phases in speech. The pulmonary phase creates the energy flow with inflation and expulsion of air. This activity provides the larynx with a column of air for the laryngeal phase in which vocal cords vibrate at certain frequencies to create sound that is unique to the individual. The oral phase occurs in the oral cavity where sound is modified words are formed by the action of the pharynx, tongue, lips and teeth. Dysfunction in any of these can lead to voice changes, which may be interpreted as hoarseness by the patient. Disorders originating in either the lung or oral cavity are not considered to be true hoarseness. True hoarseness from a laryngeal origin usually results in rough raspy voice ${ }^{1}$.

Hoarseness can be divided into acute and chronic onset ${ }^{3}$. Acute onset is more common and is often caused by local inflammation of the larynx such a seen with acute laryngitis. It may be secondary to viral infection, voice abuse, smoking, or trauma ${ }^{4}$ to larynx, thyroid surgery. Chronic onset may be caused by polyp, vocal cord nodules, laryngeal papillomatosis, tumors of vocal cord, functional dysphonia, smoking, voice abuse, gastroesophageal reflux ${ }^{5}$, postnasal drip, malignant 
neoplasms of thyroid, oesophagus, lung, neurological involvement by systemic diseases such as diabetes mellitus ${ }^{6}$ and chronic granulomatous diseases such as tuberculosis ${ }^{7}$.

While evaluating a patient with hoarseness the duration of symptoms and progression is important. This determines whether the process is acute or chronic. If the history and examination fail to provide a clear picture visual examination of larynx with laryngoscope is necessary. The valuable information can be obtained by examination with flexible laryngoscope which is performed under local anesthesia but the limitation is that it is not possible to perform surgical manipulations like dilatation, vocal cord injection and biopsy can not be performed. Other endoscopic procedures used to evaluate the larynx prior to direct laryngoscopy are videolaryngoscopy and videolaryngostroboscopy. These are best ways to assess the dynamic functions of the larynx as observations during quite breathing and during a variety of tasks are possible. Direct laryngoscopy is required for additional evaluation of suspected or actual pathology within the larynx, therapy within the larynx like removal of vocal cord poyps, diagnostic purpose like taking biopsy or as a preliminary step to intubation².

\section{MATERIAL AND METHODS}

It was a prospective study conducted upon 200 patients suffering from hoarseness of voice in the department of ENT Allied hospital Faisalabad from Jan 2001 to Dec 2004. The detailed history, clinical examination, routine investigations and special investigations were carried out to find the etiology. Standard performa was prepared duly filled for each patient. All the patients of hoarseness of voice in the study were selected randomly. The follow up of cases was carried out from 6 months to 36 months. The data was compiled and conclusions were made. The etiological factors were classified as infections, neoplasms, trauma, chronic infections, metabolic and drugs.

\section{RESULTS}

Total 200 patients suffering from hoarseness of voice 150 males (75\%) and 50 females (25\%) between 10 to 70 years of age. The highest incidence was seen in males during third, fourth and fifth decade of life (65\%).The incidence of hoarseness of voice was 50 cases per year. The majority of cases were admitted through out patient Department (75\%).

\begin{tabular}{|l|c|c|}
\hline \multicolumn{3}{|c|}{ Table-I. Sex distribution of patients $\mathrm{n}=\mathbf{2 0 0}$} \\
\hline Sex & No of patients & $\%$ age \\
\hline Male & 150 & $75 \%$ \\
\hline Female & 50 & $25 \%$ \\
\hline Total & 200 & $100 \%$ \\
\hline
\end{tabular}

Table-II. Distribution of patients according to age $(n=200)$

\begin{tabular}{|l|c|c|}
\hline Age (years) & No of patients & \%age \\
\hline 10 to 30 years & 30 & $15 \%$ \\
\hline 31 to 50 years & 130 & $65 \%$ \\
\hline 51 to 70 years & 40 & $20 \%$ \\
\hline
\end{tabular}

Table-III. Distribution of patients according to the etiology $(n=200)$

\begin{tabular}{|l|c|c|}
\hline Etiology & No of pts & $\%$ age \\
\hline $\begin{array}{l}\text { Non specific acute and chronic } \\
\text { laryngitis }\end{array}$ & 40 & $20 \%$ \\
\hline Blunt neck trauma & 30 & $15 \%$ \\
\hline Thyroid surgery & 25 & $12.5 \%$ \\
\hline Profession (Vocal abuse) & 25 & $12.5 \%$ \\
\hline Laryngeal carcinoma & 22 & $11 \%$ \\
\hline Tuberculous laryngitis & 20 & $10 \%$ \\
\hline Endotracheal tube trauma & 15 & $7.5 \%$ \\
\hline Bronchogenic carcinoma & 6 & $3 \%$ \\
\hline Thoracic surgery & 5 & $2.5 \%$ \\
\hline Inhaled steroids & 5 & $2.5 \%$ \\
\hline Naspharyngeal carcinoma & 4 & $2 \%$ \\
\hline Hypothyroidism & 3 & $1.5 \%$ \\
\hline
\end{tabular}


The majority of patients were belonging to poor class $(75 \%)$. The majority of cases were due to infections 60 ( $30 \%$ ). In case of trauma surgical trauma was more common $45(22.2 \%)$. In case of neoplasms majority of cases were due to malignant growths $32(22 \%)$. Hoarseness of voice was the commonest symptom $200(100 \%)$.

\section{DISCUSSION}

The infections topped the list of etiological factors (30\%) causing hoarseness of voice. These were more common among adults. Among acute infections acute viral laryngitis was the commonest cause of hoarseness where as chronic non- specific laryngitis was the commonest chronic infectious cause. In all acute infective cases duration of hoarseness varied from five to seven days. On indirect laryngoscope the vocal cords were found to be swollen and hyperemic with loss of their whitish color. In chronic non specific laryngitis symptoms included hoarseness, foreign body sensation in the throat and constant desire to clear the throat. These symptoms were more in smokers and those belonging to the polluted and bad hygienic environment.

The incidence of non specific laryngitis in the study of Muhammad Aslam was $18 \%$ as compare to $20 \%$ of our study.

The incidence of laryngeal tuberculosis in our study was $10 \%$ as compare to the study of lqbal $\mathrm{K}$ et al in which it was $47 \%$.

In the category of trauma the blunt neck trauma was the first important cause of hoarseness the neck trauma was caused by road traffic accidents, strangulation, assault and fall. The incidence of hoarseness due to blunt neck trauma in our study was $15 \%$ where as it was $44.44 \%$ in the study ${ }^{10}$.

The thyroid surgery was second etiological factor which causes hoarseness due to injury to the recurrent laryngeal nerves and its incidence was $12.5 \%$ as compare to the studies of Maqbool Ahmed et $\mathrm{al}^{11}$ and $\mathrm{M}$ Arif et $\mathrm{al}^{12}$ in which it was $3.5 \%$ and $9.4 \%$ respectively.
The endotracheal tube intubation was third in the category of trauma which causes hoarseness due to injury to the vocal cords and its incidence in our study was $7.5 \%$ as compare to $55 \%, 15 \%, 32 \%, 53 \%$ of studies respectively ${ }^{13-16}$.

Thoracic surgery was last factor in trauma and its incidence was $2.5 \%$ as compare to $32 \%$ and $5.5 \%$ in the study $^{17,18}$. The different professions in which there is vocal abuse leading to vocal cord nodules such as teachers, singers, drill instructors or young boys memorizing quran etc accounts $12.5 \%$ in contrast with $17.7 \%$ in the study ${ }^{19}$.

Among the neoplastic causes majority of cases were malignant due to squamous cell carcinoma of larynx, lung and nasopharynx. The contribution of carcinoma of larynx was $11 \%$ in contrast to the study of Muhammad Aslam ${ }^{1}$ in which it was $69 \%$, the share by bronchogenic carcinoma was $3 \%$ as compare to study of Zafar Hussain lqba| $^{20}$ in which it was $21.5 \%$ and nasopharyngeal carcinoma contributed $2 \%$ in front of $44 \%$ in the study ${ }^{21}$.

The inhaled steroids are now emerging as a new entity in the etiology of hoarseness of voice because of their use over longer periods in cases of bronchial asthma and its incidence in our study was $2.5 \%$ in contrast with $14.1 \%$ the study ${ }^{22}$. Finally the contribution by hypothyroidism was $1.5 \%$ in contrast to $83.3 \%{ }^{23}$.

\section{CONCLUSION}

The etiology ranges from trivial infections to life threatening malignancies. A sequential history, physical examination and appropriate investigations can lead to appropriate diagnosis.

The hoarseness should not be ignored if it persists for more than three weeks and does not respond to conventional therapy.

\section{REFERENCES}

1. Loyn SB, Doctor my voice seems husky Auster fam physician 1994; 23: $2111-2119$.

2. Davidson EM, Clinical manual of otolaryngology, Mc Grw -Hill, New York, 2' Ed 1992. 
3. Dettelbach M, Eibling DE, Johnson JT, Hoarseness from viral laryngitis to glottic cancer, Postgrad Med 1994; 95 : 143.

4. Chagnon FP, Moulder DS, Laryngotracheal trauma, chest surg din north Am 1996:6:73-48.

5. Smit CE, Van Leeuwen JA, Mathus Vliegen LM, Devriese PP, Semen A, Tan J, Schouwenburg PF. Gastropharyngeal and gastroesophageal reflux in globus and hoarseness. Arch Otolaryngol Head Neck Surg 2000 July: $126(7): 827-30$.

6. Woodson GE, Blitzer A, Neurologic evaluation of the larynx and pharynx. In cummings $O W$ et al, Otolaryngology Head and Neck Surgery edition, St. Lous Mosby 1995: 61-17.

7. Ramazan HH, Tarazi ARE \& Baroudy FM, Laryngeal tuberculosis presentation of 16 cases and review of literature. J Otolaryngol $1993 ; 22: 39-41$.

8. Muhammad Aslam, Hoarseness and laryngeal pathology, Pakistan J Pathology Jun 1996:7(2): 20-3.

9. Iqbal $\mathrm{K}$ et al, Laryngeal involvement in pulmonary tuburculosis J Pak Med Assoc 1996 Dec 46(12);274-6.

10. Muhammad Zafar, Danyal Rashid et al, Blunt external laryngeal trauma clinical analysis And management experience, at $\mathrm{CMH}$ Rawalpindi Pakistan $\mathrm{J}$ Otolaryngol Jun 2002;18(2):23-5.

11. Maqbool Ahmed Mumtaz Ahmed et al, Surgical audit of solitary thyroid nodule, Pak Armed Forces Med J, Dec 2001; 51(2): 106-10.

12. Muhammad Arif, Imtiaz Ahmed, Recurrent aryngeal nerve paralysis during thyroidectomies, $\mathrm{J}$ surg Pakistan Sep $2001 ; 69$ (3): $12-5$.

13. Maruyama K, Sakai H et al, Sore throat and hoarseness after total intravenous anaesthesia, British $\mathrm{J}$ Anaesth
2004 April 92 (4) $541-3$

14. Benuett MH, Isert PR et al, Post operative sore throat and hoarseness following tracheal intubation using air or saline to inflate the cuff a randomized controlled trial Anaesth Intensive care, 2000 Aug 28 (4); 408 - 13.

15. Jones MW, Catling $S$ et al, Hoarseness after tracheal intubation Anesthesia 1992 Mar; 47(3); 213 -6.

16. Abdulla Mohsin et al, Complications of endotracheal intubation in open heart surgery patients, Ann King Edward Med Coll Jun 2000; 2 (6); 176 - 8.

17. NIIMI, SEIJI, Vocal'cord paralysis after thoracic aortic aneurysm, surgery Chest $6-1-2002$.

18. Amir Bilal, M Saleem et al, An experience of 108 cases of oesophagectomy using left thoraco laparotomy and cervical anastomosis with feeding jejunostomy without gastric drainge procedure, Ann King Edward Med coil, Dec 2004; 10 (4); 330 -4.

19. Preciado JA, Gascia Tapia R el al, Prevalence of voice disorders among educational professionals factors contributing to their appearance or their persistence, Acta Otorrinolaringol esp 1998 Mar49 (2); 137-47.

20. Zafar Hussain lqbal, Presentation of lung cancer in south of Punjab Biomedical Jun 1997; 13(1); 6- 10.

21. Imad, Mahid lqbal et al, Presentation of nasopharyngeal carcinoma, J Post Grad Med Inst Jun 2005; 19 (2) ; 212 -5 .

22. Dubus JC, Marguet et al, Local side effects of inhaled corticosteroids in asthmatic children influence of drug, dose, age and device Allergy Volume 56, Number 10, October 2001 pp. 944-948(5).

23. Bashir Ahmed, Tahir Hussain et al, Clinical presentations of hypothyroidism, J Coil Physicians Surg Pak, Nov 2001 ii (11);676-8. 